\title{
IDÉIAS
}

\section{Risco de duplicação da burocracia existe}

\author{
Prof. Uwe Thayssen
}

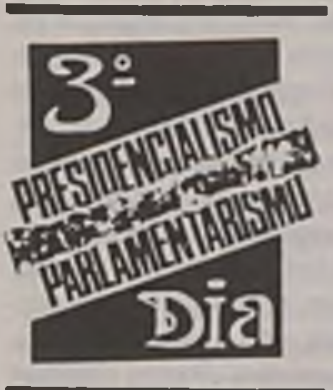

Quando aqui cheguei, parti do princípio que teria que relatar sobre um sistema político, ou seja, sobre o sistema político da República Federal da Alemanha. Quanto mais assistia às conferências e debates, tanto mais aprendia sobre seus problemas aqui no Brasil, e mais me convencia de que deveria relatar sobre dois sistemas, a saber, sobre o sistema da República de Weimar e sobre o da República Federal da Alemanha. Este último não poderia ser entendido sem os erros da República de Weimar e porque, no Brasil, exatamente este problema tem um importante papel, ou seja, o que diz respeito a quantas competências e direitos deve ter o Presidente e quantas competências e direitos deve ter o Parlamento. Neste ponto, exatamente aqui, os criadores da Constituição de 1949 muito tiveram que aprender da História da República de Weimar. Irei abordar, portanto, dois sistemas políticos, como dito, o da República de Weimar, de 1919 até 1933, e o da República Federal da Alemanha, de 1949 até hoje. Inicialmente, gostaria de dizer o que pretendo também mencionar aqui. Penso que lhes devo uma definição do que eu, no decorrer da conferência, quero entender com o conceito de regime governamental parlamentarista e presidencialista.

$\mathrm{Na}$ primeira parte, abordaremos a filosofia e os princípios básicos de sistemas políticos. Desejo, então, numa segunda parte, fazer uma descrição concreta da República de Weimar e da República Federal da Alemanha e, na terceira parte, falar de uma especificidade do sistema político da República Federal da Alemanha, ou seja, sobre a combinação de federalis-

Uwe Thayssen é professor titular da Universidade de Hamburgo e redator-chefe da Revista de Assuntos Parlamentares de Hamburgo. Conferencista do 3: Dia.

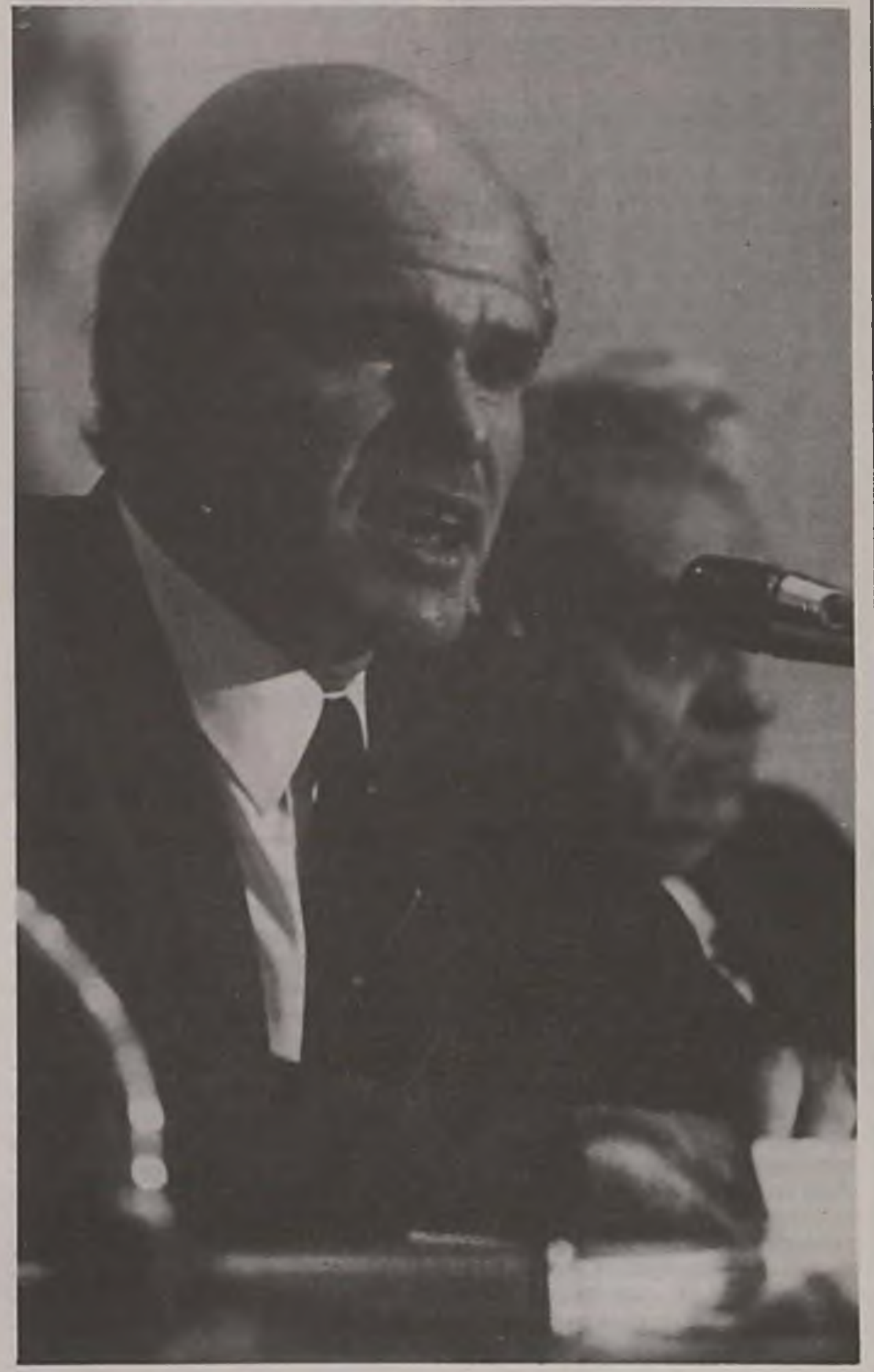


mo e parlamentarismo, porque a República Federal da Alemanha é um dos poucos paises do mundo onde existe um parlamentarismo e federalismo combinados. Este fato merece algumas considerações. Finalmente, poderia ser útil oferecer-lhes alguns detalhes mais técnicos, alguns dảdos, que fornecem informaçōes sobre que tipo de despesa com administração, com burocracia e com projetos científicos, no caso do sistema presidencialista e do sistema parlamentarista de governo. Estes são os quatro pontos que gostaria de abordar aqui.

Primeiro, quanto à parte mais teórica, filosófica e conceitual. Sob o ponto de vista histórico, a forma básica do sistema presidencialista de governo se formou nos Estados Unidos. O protótipo do sistema parlamentarista, ao contrário, surgiu na Grã-Bretanha. O que diferencia, essencialmente, estes dois tipos ideais diz respeito a um critério decisivo, caso se quisesse limitar a um critério onde esses dois sistemas, o sistema dos Estados Unidos, por um lado, e o da Grã-Bretanha, por outro, divergem. Existem muitas caracteristicas, mas, quando se tem que citar um critério decisivo, que inclua as outras caracteristicas de diferenciaçãu, que condicione e também esclareça, então, chegamos à conclusão de que, nos sistemas presidencialistas, o Parlamento não tem condiçōes de demitir o governo, não tem condiçỏes de demitir o chefe de governo. É este, exatamente, o critério decisivo para sistemas parlamentaristas: o governo pode ser destituido pelo Parlamento. Em todos os sistemas de que falamos até o montento, 10 mos fatores característicos de presidencialismo e parlamentarismo. Contudo, se quisermos diferenciar o sisterna parlamentarista do sistema presidencialista, isto deve ser feito, basicamente, segundo o critério de que, no parlamentarismo, o Parlamento pode demitir o governo, enquanto no presidencialismo isto não $\varepsilon$ possível. Este critério de diferenciação carrega consigo muitos outros. A House of Commons pode, a qualquer hora, demitir o Primeiro-Ministro, assim como o Chanceler alemão pode ser demitido a qualquer momento. Por isso, o sistema da Alemanha Ocidental é parlamentarista e não presidencialista, apesar da República Federal da Alemanha possuir um presidente. Como o Prof. Young expôs, o sistema presidencialista dos Estados Unidos da América e outros sistemas presidencialistas dependem da cooperação Congresso-Presidente. Os sistemas parlamentaristas, ao contrário, objetivam, principal- mente, a integração. Sistemas presidencialistas são baseados, segundo sua filosofia interna na cooperação; sistemas parlamentaristas, mas nítida e intensivamente, na integração. Minhas senhoras, meus senhores, está é, principalmente, uma característica constitucional de diferenciação. O Prof. Young dos EUA já elucidou, através da História, que, na prática constitucional podem surgir situações - que na verdade surgiram - que destoam deste modelo. Eu também vou apresentar o mesmo para o caso da República Federal da Alemanha.

No sistema presidencialista, domina o sistema do executivo unificado e homogêneo. No Parlamento, ao contrário, existe, geralmente, um executivo duplo. O Presidente americano é o chefe de estado,

A diferença mais fundamental
entre os dois sistemas é que
no parlamentarismo o
Parlamento pode demitir o
governo, no presidencialismo
não. Este precisa da
cooperação entre Congresso e
presidente mas o
parlamentarismo ao contrário
busca a integração deles.

chefe de governo e único ministro numa pessoa. Nos paises latino-americanos existe, às vezes, ao lado do presidente, um conselho de ministros ou um tipo de conselho federal. Um bom conhecedor das constituiçōes e sistemas políticos da América Latina, Löwenstein, disse, certa feita, que esse conselho de ministros ou conselho federal, na maioria das vezes, é concebido como "freio" do poder presidencial. Nos sistemas parlamentaristas, que como dito, normalmente possuem um executivo duplo, existe, ao lado do PrimeiroMinistro, ou seja, ao lado do chefe do governo, normalmente, um chefe de estado, na figura de um monarca ou de um presidente. Como os senhores sabem, a GrãBretanha é um exemplo de executivo duplo, um Primeiro-Ministro e o Monarca.
Igualmente, os países escandinavos e Holanda são exemplos de executivo duplo, enquanto a República Federal da Alemanha é um exemplo republicano, onde se precisa de um presidente no lugar de um monarca. A caracteristica decisiva da diferenciação de democracias presidencialistas e parlamentaristas não é, portanto, se nelas existe ou não um presidente. Os dois protótipos também não se diferenciam pelo fato de, neles, o presidente ou o parlamento serem fortes ou fracos. Isto é passivel de alteração sob o ponto de vista histórico; está subordinado a condições históricas. $\mathrm{O}$ critério decisivo para diferenciação de ambos os protótipos é, principalmente, repito, se o Parlamento pode destituir o chefe de governo ou não. Onde isso é o caso, temos o sistema parlamentarista; onde não, o sistema presidencialista. Se queremos citar os sistemas presidencialistas como exemplos concretos, então é preciso ser dito que o Império alemão era um sistema presidencialista. No Império, o chanceler não podia ser destituido pelo Parlamento. As formas republicanas de sistemas presidencialistas são, como dito, segundo as características de diferenciação por mim mencionadas, os EUA, os países latino-americanos e, como o Embaixador Silva já apresentou, também o sistema suíço. Na Suiça temos um Bundestat (conselho federal) como governo, e este conselho não pode ser destituido pelo Parlamento suiço (Bundesversammlung). Sistemas parlamentaristas são, assim, Grã-Bretanha, Escandinávia, Holanda e eram a Terceira República Francesa, a Quarta República Francesa; também a Quinta República Francasa é, finalmente, um sistema de governo parlamentarista, porque o Premier pode ser demitido pelo Parlamento. Conforme ouvimos da exposição do Professor Jean Luc Parodi, temos, porém, uma forte hegemonia presidencial no sistema francês.

Esta foi apenas uma tentativa de diferenciar o presidencialismo do parlamentarismo, porque os dois termos não possuem em si muito valor conceitual. O que é decisivo é a combinação desses dois poderes na democracia.

Peço desculpas, pois essas considerações mais constitucionais são menos empolgantes do que História e histórias. Por isso, quero passar para a história do sistema parlamentarista na República Federal da Alemanha.

Quando recebi este honroso convite, refleti por que os senhores poderiam querer convidar alguém da Alemanha. A Alemanha, certamente, não é um modelo de 
democracia; pelo menos não é conhecido históricamente como tal. Sob este aspecto não serve como padrão para os esforços de institucionalização de sistemas de governos democráticos. Todavia, à medida em que assistia aos debates e conferências, tive a impressão de que exatamente esta deve ter sido a razão do convite a um alemão. Na Alemanha, já fizemos duas tentativas para institucionalizar um sistema democrático. Uma, há exatamente 80 anos. A partir de 1917 , depois da Primeira Guerra Mundial, fizemos um esforço para estabelecer a democracia na Alemanha. A segunda tentativa foi há 40 anos, quando nossa Assembléia Constituinte se reuniu para elaborar nossa Constituição. Tal como os senhores, que agora refletem, aqui no Brasil, sobre qual constituição adotar, também nós fizemos, em 1917 e 1947, reflexões análogas. As situações históricas eram comparáveis em vários aspectos. Os novos sistemas políticos a serem estabelecidos em $1917 \mathrm{e} \mathrm{em}$ 1947 tinham imensas tarefas a cumprir: em 1917, superar as conseqüências da Primeira Guerra Mundial e, em 1947, superar as conseqüências ainda mais terriveis da Segunda Guerra Mundial. Em ambos os casos, portanto, precisava-se estabelecer um sistema de governo que possibilitasse, efetivamente, a solução de muitos problemas; um sistema de governo que fosse eficaz tanto em 1917 quanto em 1947.

Uma das razōes por que irei falar da República de Weimar é, obviamente, que a Constituição de 1917 não atendia às exigências do seu tempo. A Constituição de 1949, porém - quero ser cauteloso ainda tem condições de afirmar-se. Acredito que se possa dizer que os constituintes de 1947 criaram uma Constituição realmente útil.

Permitam-me esclarecer, brevemente, as estruturas básicas do sistema de Weimar, principalmente com relação à questão dos direitos que o Presidente tinha naquela república e os direitos do Parlamento. Em 1919, era um sistema de governo. no início, que se seguiu a uma monarquia. A grande questão era que precisavam de um tipo de "substituto do imperador", porque, naquela época, os partidos estavam bastante divididos. Os partidos pareciam irresponsáveis para os teóricos da constituinte e para muitos políticos. A conseqüência que dai adveio foi que passamos a precisar de uma personalidade forte que pudesse dominar o caos. Com esses partidos bastante fragmentados, que não possibilitavam nenhum tipo de coe- são, precisávamos, portanto, de uma pessoa forte, uma instituição forte que, de forma temporária, pudesse agir quando - Parlamento não tivesse condiçōes para tal: um "imperador substituto".

Surgiu, então, na Constituição, o Presidente como um tipo de imperador substituto, que obteve muitos direitos semelhantes àqueles dos monarcas em um sistema monárquico; não numa monarquia constitucional, mas num sistema monárquico.

O Presidente da República de Weimar foi eleito, assim, diretamente. Ele tinha sua própria base de poder, sua própria base de legitimação. Por isso tinha muita autoridade. Além disso, ele tinha o direito de nomear o chanceler do Império, portanto, o chefe do governo. Este é, também.

\begin{tabular}{|c|}
\hline \\
Os dois termos - \\
presidencialismo e \\
parlamentarismo - não \\
possuem em si muito valor \\
conceitual. O que é decisivo é \\
a combinação desses dois \\
poderes na democracia. A \\
diferença decisiva das duas \\
democracias não é se nelas \\
existe ou não presidente.
\end{tabular}

um critério muito importante: 0 direito de dissolver o Reichstag (parlamento) sob condições especiais. Tinha, ainda, o direito de promulgar decretos-leis sem a participação do Parlamento.

Existem, na República de Weimar, quatro direitos, portanto, que muito fortalecem o presidente; primeiro, sua eleição direta: segundo, o direito de nomear o chanceler; terceiro, o direito de dissolver o Parlamento; e quarto, promulgar decretos-leis. Os partidos da República de Weimar sabiam, deste modo, que, se eles não funcionassem, o presidente interferiria, o "imperador substituto" viria e agiria. Eles nāo tinham, portanto, que ser responsáveis; podiam se permitir fugir da responsabilidade. Uma das razões do fracasso da República de Weimar é, entre muitas, que o sistema político estabelecido naquela época nāo forçou os partidos a participar da responsabilidade politica. Eles até podiam demitir o chanceler sem ter que eleger um outro. Assim, pode-se dizer que o sistema político de Weimar estava elaborado de tal forma que não educava os partidos para a responsabilidade, não obrigava os partidos a se responsabilizarem. Esta foi a oportunidade para que presidentes, com tendências antidemocratas, agissem de maneira autoritária desde 1930.

Inicialmente, os partidos demonstraram incompetência para criar governos eficazes. Interveio, então, o imperador substituto, o presidente, nesse vazio, nesse vácuo: dissolveu o Reichstag e, sem o consentimento deste, designou o chanceler. Governou com ajuda dos decretos-leis. Esta foi uma fase de política autoritária, fase que precedeu imediatamente ao fascismo de Hitler. Friedrich Ebert foi, entretanto, um presidente que utilizou democraticamente os direitos presidenciais. Nào se pode dizer, assim, que o poder do presidente na República de Weimar tenha trazido, necessariamente, a ditadura, mas deve-se dizer que facilitou a ditadura e o barbarismo de Hitler, que foi entronizado por Hindenburg.

É essa a situação que os constituintes de 1947 tinham a sua frente; sobre ela refletiram, quando elaboraram a Constituição da República Federal da Alemanha em 1949. Eram democratas, que sofreram nos campos de concentração e que estiveram exilados. Por isso, absolutamente não queriam criar um sistema que facilitasse o caminho para um autoritarismo ou mesmo preparasse o caminho para uma ditadura. Extrairam das conseqüências da História da República de Weimar e do nacional-socialismo, a lição de, em primeiro lugar, dar ao presidente pouco poder e, em segundo, de induzir, institucionalmente, os partidos políticos à responsabilidade. Os constituintes queriam uma estrutura que não desse aos partidos a possibilidade de fugir à responsabilidade; queriam uma estrutura que possibilitasse coligaçōes, a criação de maiorias, para estabelecer um gaverno que atuasse eficientemente.

Os constituintes de 1949, portanto, os pais da Constituição ainda hoje em vigor na Alemanha, queriam um sistema parlamentarista eficaz e com condições para agir; um governo forte que, ao mesmo tempo, deveria ser controlado pelos partidos democraticamente, ou seja, um governo parlamentarista. Elaboraram, por- 
tanto, uma estrutura que é única no mundo entre os sistemas constitucionais, em que criaram o voto de desconfiança construtiva, isto é, o Parlamento só pode demitir o chefe de governo, e assim o governo como um todo, quando eleger ao mesmo tempo um novo chefe de governo. Isto significa que os partidos não podem se omitir. Não existe a possibilidade, como na República de Weimar, de a extrema direita e a extrema esquerda se aliarem e mandarem o governo para casa, sem colocar um novo na função.

Essa situação de Weimar possibilitava uma maioria destrutiva, enquanto na $\mathrm{Re}$ pública Federal da Alemanha criamos um sistema onde pressupomos, permanentemente, uma maioria construtiva. Não existe a possibilidade de o Parlamento dizer que não é responsável; de demitir o chanceler, sem eleger um outro. Assim como não pode dissolver o Parlamento (só em determinadas situações, às quais não quero reportar-me aqui, por não serem comuns). Não existe a possibilidade de o Parlamento dizer que vai se dissolver; ao contrário, ele tem que se manter unido, tem que eleger um governo e tem que controlá-lo. Esta cláusula é bastante específica. Denomina-se "voto de desconfiança construtiva"; está no artigo 67 da Constituição da República Federal da Alemanha.

Minhas senhoras, meus senhores, acredito que, neste recinto e entre os debatedores, existe um mito, ou seja, o de que os sistemas parlamentaristas não formam grandes lideres politicos, os Führer - pessoalmente, odeio essa palavra "Führer" por sua conotação na língua alemà. Isto é um mito, não está correto. Max Weber e muitos outros queriam sistemas parlamentaristas, porque os observaram na Grā-Bretanha, na França, onde conheceram lideres como Lloyd Georg, Clemenceau, Wilson e outros, que foram eleitos num sistema parlamentarista $c$, com exceção de Wilson, tinham um grande apoio de plebiscito junto ao povo. O prérequisito para uma forte personalidade carismática, como disse Max Weber, era exatamente a criação de um sistema parlamentarista. É preciso ser dito, então, que um parlamento forte é um pressuposto para que um lider politico forte tenha chance.

Há, ainda, um outro mito, a saber, o de que o parlamentarismo necessariamente está ligado à fragmentação e à incapacidade de agir politicamente. Isto não tem que ser assim. É preciso construir os sistemas de tal forma que os partidos que neles atuam, sejam forçados a agir de forma responsável. Penso que a estrutura constitucional da República Federal da Alemanha, como resposta à situação de Weimar, era útil sob este ponto de vista. Ela forçou os partidos da Alemanha e apresentarem líderes políticos capazes de agir.

A Repúbica Federal da Alemanha é um sistema de governo parlamentarista e, apesar disso, é muito estável. ela é caracterizada, exatamente, pela sua estabilidade, que é reconhecida não só no contexto europeu, como também no contexto mundial, e se destaca na História alemã. Até hoje tivemos apenas dezesseis equipes ministeriais diferentes, e, em quarenta anos, apenas seis chanceleres. Não é errôneo admitir que, pelo menos, dois desses chan-

Existe um mito de que os sistemas parlamentaristas não formam grandes lideres políticos: isto é apenas um mito, não está correto. Um forte Parlamento é um pressuposto para que um lider político forte tenha chance.

celeres foram personalidades históricas, que poderão sobressair no julgamento histórico. Dependendo do critério que cada um possua, pode-se mencionar até três ou quatro.

Pode-se, portanto, resumir que o sistema parlamentarista da República Federal da Alemanha tem se revelado estável, tem se mostrado capaz de fazer lideranças politicas. Sob o ponto de vista alemão, não é necessário um sistema presidencialista quando se quer estabilidade, não necessariamente um sistema presidencialista, quando se quer ter uma forte lideranca politica. Isto, portanto, pode ser deduzido da História da República Federal.

Não quero, aqui, adentrar-me nas particularidades do sistema politico alemão. Quero apenas dizer que qualquer parla- mento tem que preencher, no minimo, cinco funções; primeiro, a função eleitoral, isto é, eleger um governo; segundo, a função de articulação, ou seja, articular em interesse da população, concretizá-lo e fazer vigorar esse interesse; terceiro, a função de iniciativa, isto é, a função da iniciativa política; quarto, a função de controle; e a última, não menos importante, a função legislativa.

Não quero abordar como estas funções realmente foram exercidas na Alemanha. É preciso considerar que todas formam um contexto, estão interligadas. $O$ fator mais importante nesse sistema político pelo que entendi aqui, o mais importante para os senhores - é a função eleitoral. Segundo a constituição, o parlamento deve eleger o chefe do governo. $O$ fato é que os partidos nomeiam um candidato a chanceler, e a eleição para o chanceler é, ao mesmo tempo, um plebiscito.

Assim, pode-se dizer que também os sistemas parlamentaristas possuem elementos de plebiscito. Apesar de o Parlamento ter o direito de escolher o chanceler, o chefe de governo, ele não era, em muitos casos da História alemã, livre em sua escolha. O Parlamento realmente só pode escolher ele mesmo o chefe de governo quando o povo não estava seguro para decidir a quem eleger. Isso ocorreu na História alemã duas vezes, a saber, imediatamente depois da Guerra, em 1949, quando o Parlamento elegeu Adenauer e em 1969, quando também não estava nitido quem o povo escolheria para chanceler. Ai, também, o Parlamento interveio.

Em todos os outros casos a eleição do Chanceler, embora a Constituição preveja algo bem diferente, tem sido, de fato, um tipo de plebiscito. Da mesma forma, no sistema parlamentarista, o chefe de goveno é eleito de forma plebiscitária. A vantagem do sistema parlamentarista, na minha opinião, consiste no seguinte: quando a eleição não se der de forma clara, ou seja, quando não se puder conhecer claramente qual o chefe de governo desejado pelo povo, o Parlamento poderá sempre intervir, em substituição. Igualmente, quando o chanceler ou chefe de governo se enfraquece, não tendo mais condição de agir, chega a hora do Parlamento intervir, escolhendo, de seu próprio grupo, um chefe de governo que ele considere o melhor e melhor do que aquele que $o$ antecedeu.

Isto aconteceu várias vezes na República Federal da Alemanha. Quando Adenauer ficou muito velho e, por causa de sua idade e alguns outros problemas, fi- 
cou sem condiçōes de governar, o Parlamento, isto é, a maioria, elegeu um novo chanceler. Quando Willy Brandt estava com problemas politicos e pessoais e os mesmos foram percebidos pela opinião pública, de tal forma que todos reconheceram a necessidade de um novo chanceler, foi a facção da maioria que trouxe para a função o novo chanceler, ou seja, Helmut Schmidt, em 1974.

Isto significa que, num sistema parlamentarista, o chefe de governo pode, a qualquer hora, ser substituido por um melhor. Essa considero uma enorme vantagem do sistema parlamentarista. Este sistema na República Federal da Alemanha foi eficaz, porque substituiu o governo logo que ele ficou incapacitado para agir, pois não estava suficientmente forte. Tornou-se uma prática substitutiva para - governo. No sistema parlamentarista, não se precisa esperar que termine o mandato de um Nixon ou de qualquer outro presidente; pode-se, institucionalizar imediatamente um melhor governo, quando surgem novos problemas, novas exigências, ou quando o chefe de governo se enfraquece, comprovando não estar mais em condiçōes de exercer essa exaustiva função.

Essa possibilidade de substituição, ou seja, a possibilidade que tem o Parlamento de intervir, eleger e determinar novo governo, no meu ponto de vista, é a grande vantagem do sistema parlamentarista sobre o presidencialista. Todas as outras funçōes que jả mencionei, como de articulaçào, de iniciativa, podem ser assumidas pelo Parlamento quando o chefe de governo não tem mais condiçōes de fazê-lo. Geralmente, o chefe de governo é, ao mesmo tempo, membro do Parlamento - deputado - ou seja, carne da carne do Parlamento, e, se possivel, o melhor pedaço de carne, da carne da maioria.

\section{O PROCESSO LEGISLATIVO NO PARLAMENTARISMO E NO PRESIDENCIALISMO}

Quero dizer algumas palavras sobre conteúdos e dados técnicos que diferenciam esses dois sistemas. Com isso, abordo a função legislativa. No sistema parlamentarista, não existe a divisão de poderes como no sistema presidencialista; a equipe central da maioria parlamentar e o governo, que, na verdade, nada mais é que o melhor grupo do Parlamento. Governo e maioria do Parlamento formam uma unidade que se contrapōe à minoria. Não é uma confrontação de aqui, o Parlamento e, là, o governo, mas é a confrontação, de um lado, governo e maioria, do outro, oposição. Isto significa que, no sistema parlamentarista, a iniciativa legal parte do governo. Três quintos de todas as leis - na Grä-Bretanha ainda mais são apresentados pelo governo; elas não são preparadas pelo Parlamento e por ele incentivadas, mas elaboradas pelo governo, na administração. O Parlamento assessora essas leis, avaliando-as mais do que elaborando-as. Ele é apenas o eco da vontade do povo. É o monitor que con-

O parlamentarismo tem elementos de um plebiscito. Nele, o Chefe do Governo pode, a qualquer hora, ser substituido por um melhor. Considero essa uma enorme vantagem do sistema parlamentar.

Esse sistema foi eficaz na Alemanha pois substituiu governos que não estavam fortes.

trola democraticamente o processo legislativo e as leis até que ponto elas são passiveis de consentimento e sua receptividade lá fora. Mas não elabora ele mesmo essas leis, pois três quintos de todas leis são apresentadas pelo governo. Bastante diferente é o sistema presidencialista.

Isso tem sua repercussão com relação à técnica legislativa e ao aparelhamento dos parlamentos. Se o Parlamento, nos sistemas presidencialistas como os Estados Unidos, elabora as leis, vota-as e as promulga, então precisa para tal de um aparelho administrativo imenso. Precisa, além da administração por parte do Executivo, um tipo de "counter bureaucracy", uma antiburocracia. No sistema presiden- cialista, como nos Estados Unidos, existem, portanto, duas burocracias: uma por parte do Executivo e outra por parte do Legislativo, ou seja, do Parlamento.

Tendo já comparado os dois sistemas em um livro, tenho à disposiçāo dados que desejo mencionar para evidenciar a diferença entre o volume de pessoal administrativo nos dois sistemas. No Congresso americano, existem 11.419 funcionários, mais cinco mil assistentes e funcionários particulares dos senadores e deputados, formando um total de aproximadamente dezenove mil, que auxiliam o Congresso nos seus trabalhos, no seu funcionamento, no cumprimento de suas tarefas. Existem ainda muitas agências ou instituições particulares como Congressional Research Service, General Accounting Office, Congressional Buōget Office, Office of Technology Assessment, etc. Todas essas instituiçōes são necessárias para que, no sistema presidencialista, o Congresso possa cumprir suas tarefas.

Caso os senhores indaguem sobre que tipo de sistema adotar no Brasil, surge tambem a pergunta: os senhores têm possibilidade de formar uma equipe como esta a que nos referimos? É isso realmente que os senhores querem? Querem institucionalizar tal "contraburocracia" à burocracia do governo, ou não?

Um sistema oposto seria o do sistema parlamentarista da Grã-Bretanha e da República Federal da Alemanha. A House of Commons tem muito menos pessoal, muito menos prestação de serviços que o Bundestag (parlamento alemão). Este, de certa forma, é uma mistura e tem um sistema de comissōes bem elaborado. $\mathrm{Na}$ Grã-Bretanha existem poucos funcionários no Congresso ou servidores parlamentares. Na Alemanha temos no total dois mil membros de diferentes setores de prestação de serviço. Não precisamos de pareceres como no sistema presidencialista, porque a maioria do Parlamento tem acesso aos dados do Executivo, e o Parlamento como um todo tem acesso à administração. Por isso, não existe, no sistema parlamentarista, essa duplicação de administração burocrática por parte do executivo e do Congresso. No sistema parlamentarista, a despesa com administração apenas é necessária por parte do executivo; por parte do Parlamento só pode haver um pequeno contingente.

Uma última palavra sobre o aspecto técnico da legislação. Em sistemas presi- 


\section{IDÉIAS}

dencialistas, existe um grande número de projetos que devem ser tratados no Parlamento. Nos sistemas parlamentaristas, ao contrário, existem muito menos projetos porque estes são apresentados principalmente pelo governo. Se compararmos - Congresso americano e o Bundestag certamente tal comparação seria deficiente - teremos a seguinte situação: no $98^{\circ}$. Congresso americano, isto é, no Congresso de quatro anos atrás, foram apresentadas 9.769 projetos de lei. É uma quantidade enorme. Destes 9732, portanto apenas pouco menos, foram passados para as comissōes. E, das comissōes, apenas 1529 foram devolvidos ao Plenário. Do processo de filtragem legislativa decorre que apenas poucas leis são, realmente, promulgadas. Apenas poucas leis saem das comissões são julgadas na Câmara, depois no Senado, então em sessão conjunta. No final, o que resta são muito poucas leis. Isto não é motivo de queixa, porque isso é exatamente o que Madison e seus constituintes queriam.

Surge, porém, a questão: um Congresso num pais como a Alemanha, que passava por um periodo pós-guerra e onde efetivamente havia muito por se fazer, como é o caso do Brasil, está em condiçōes de se dar o luxo de ter um sistema presidencialista, onde a diversidade de projetos abre a possibilidade de um bloqueio? Será que um Parlamento aqui teria condições de trabalhar com tantos projetos, segundo o modelo presidencialista? Ou seria mais valioso levar em consideração um sistema parlamentarista, onde as linhas entre as leis apresentadas e as pronulgaçòes são praticamente paralelas, apenas pouco diferenciadas?

O número de leis que são apresentadas na Alemanha é apenas um pouco mais elevado do que o número de leis promulgadas, porque o governo previamente as testou em seus partidos e através de muitos outros métodos. Como se pode ver, sistemas politicos diferentes produzem também uma diferenciada despesa técnica legislativa. Penso que, aqui no Brasil, se deveria achar a resposta adequada: o que se pode e se quer despender com burocracia? O que se poderia realizar em termos de trabalho legislativo?

Minhas senhoras, meus senhores, com essas perguntas e com o que queria esclarecer com os exemplos alemães, termino minha exposição, desejando que os senhores encontrem a melhor solução. Falando por todos os colegas que aqui puderam dar suas palestras e suas contribuiçōes, esperamos ter ajudado de qualquer forma. Desejamos muito sucesso em seus esforços. Gostaria de agradecer também ao intérprete, que inicialmente veio para traduzir alemão, mas que também traduziu para o inglês; a ele também meus agradecimentos.

Vejo que os senhores aqui no Brasil, com seus vinte e quatro estados, deveriam estar interessados em saber como convivem, na Alemanha com seus onze Estados, o parlamentarismo e o federalismo. Quero concentrar-me apenas no efeito do federalismo, descrevê-lo e apresentar os pressupostos instituicionais o mais resumidamente possivel.

Diferentemente do Senado americano, os membros de nossa Segunda Câmara do Bundesrat (conselho federal) não possuem

\begin{tabular}{c}
\hline O número de leis \\
apresentadas na Alemanha, \\
no Bundestag, é apenas um \\
pouco mais elevado do que o \\
múmero de leis promulgadas, \\
porque o governo as testou \\
previamente em seus partidos, \\
e através de muitos outros \\
métodos. Apenas poucas leis \\
passam.
\end{tabular}

urn mandato livre. Não temos no Bundesrat, nossa Segunda Câmara, o principio de Senado, mas o princípio do conselho federal, isto é, no Bundesrat os deputados não são livres, como no Senado americano, mas são delegados pelo respectivo governo estadual. Assim, não se reúnem no Bundesrat livres deputados com livres mandatos, mas delegados do governo estadual com mandato imperativo. Agora torna-se complicado: temos, a nível federal, o Bundestag ou o Parlamento como Primeira Câmara, e a Segunda Câmara, o Bundesrat que tem muitos direitos, pois deve opinar sobre todas as leis que dizem respeito a orçamento e à administração. Pergunto: que leis não dizem respeito a orçamento, que leis não dizem respeito à administração? Assim é que se o Bundesrat tem que opinar sobre a maioria das leis, o Bundestag desde o início, questiona se o Bundesrat estará ou não de acordo. O Bundesrat pode ser composto, com relação à vertente política, de forma diferente do Bundestag, isto é, no Bundesrat a oposição pode estar mais representada - já aconteceu de ela ser mais forte do que os partidos que eram a maioria no bundestag. Nesse momento teríamos na Alemanha um bloqueio, pois nada mais seria promulgado, a não ser que a maioria no Bundestag apresentasse desde o início leis que teriam a anuência do Bundesrat.

Isso, paradoxalmente, trouxe como conseqüência um consensualismo do Legislativo na República Federal da Alemanha. É único e característico da Repúblisa Federal da Alemanha, comparando com a centralização da França, com o antagonismo do sistema britânico, com a Itália e com quase todos os outros paises europeus, que $75 \%$ das leis são aprovadas por unanimidade. A legislação e a política na República Federal da Alemanha formam uma impressionante unidade comparada ao sistema presidencialista e, também, à maioria dos sistemas parlamentaristas. Isto se deve, essencialmente, à existência da Segunda Câmara. Mas o federalismo alemão tem um outro efeito. Os partidos que governam em Bonn não têm, necessariamente, que governar nos Estados, isto é, a oposição nunca tem condiçōes de se tornar ideológica, extrema, perder o nível pragmático, porque ela talvez nos Estados constitua o governo.

Assim, os partidos na República Federal da Alemanha, graças a essa estrutura federativa, são partidos responsáveis. Este sistema permite que os partidos oposionistas a nível federal possam assumir o governo a nível estadual. Ele convoca os partidos a comprovarem responsabilidade política, não partindo para extremos, mas permanecendo competitivos em torno do centro, mais conservadores, centralizando e moderando os programas políticos. É antes uma tendência para o centro do que uma competição entre os partidos para os extremos. Este é um dos motivos porque a política na Alemanha é caracterizada pelo seu alto consenso. É um efeito paradoxal, que exatamente um federalismo seja responsável por uma forte e unitária tendência para uma concentração em programas de moderação e de equiparação. É um paradoxo, mas é um efeito essencial do federalismo na República Federal da Alemanha.' 